\title{
Towards the Large-Eddy Simulation of a full engine: Integration of a 360 azimuthal degrees fan, compressor and combustion chamber. Part I: Methodology and initialisation
}

\section{Original article}

Article history:

Submission date: 16 October 2020

Final revision date: 14 December 2020

Acceptance date: 6 February 2021

Publication date: 25 May 2021

Check for updates

*Correspondence:

JD: dombard@cerfacs.fr

Peer review:

Single blind

\section{Copyright:}

() 2021 Pérez Arroyo et al. (-) This is an open access article distributed under the Creative Commons Attribution Non Commercial No Derivatives License (CC BY-NC-ND 4.0). Unrestricted use, distribution, and reproduction of the original work are permitted for noncommercial purposes only, provided it is properly cited and its authors credited. No derivative of this work may be distributed.

\section{Keywords:}

interaction; LES; compressor; combustion chamber; fan; gas-turbine engine

\section{Citation:}

Pérez Arroyo C., Dombard J., Duchaine F., Gicquel L., Martin B., Odier N., and Staffelbach G. (2021). Towards the LargeEddy Simulation of a full engine: Integration of a 360 azimuthal degrees fan, compressor and combustion chamber. Part I: Methodology and initialisation. Journal of the Global Power and Propulsion Society. Special Issue: Data-Driven Modelling and High-Fidelity Simulations: 1-16. https://doi.org/10.33737/jgpps/133115

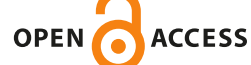

Carlos Pérez Arroyo ${ }^{1}$, Jérôme Dombard ${ }^{1,{ }^{*}}$, Florent Duchaine $^{1}$, Laurent Gicquel ${ }^{1}$, Benjamin Martin ${ }^{1}$, Nicolas Odier ${ }^{1}$, Gabriel Staffelbach ${ }^{1}$

${ }^{1}$ CERFACS, 42 Avenue Gaspard Coriolis, 31100 Toulouse, France

\begin{abstract}
Optimising the design of aviation propulsion systems using computational fluid dynamics is essential to increase their efficiency and reduce pollutant as well as noise emissions. Nowadays, and within this optimisation and design phase, it is possible to perform meaningful unsteady computations of the various components of a gas-turbine engine. However, these simulations are often carried out independently of each other and only share averaged quantities at the interfaces minimising the impact and interactions between components. In contrast to the current state-of-the-art, this work presents a 360 azimuthal degrees large-eddy simulation with over 2100 million cells of the DGEN-380 demonstrator engine enclosing a fully integrated fan, compressor and annular combustion chamber at take-off conditions as a first step towards a high-fidelity simulation of the full engine. In order to carry such a challenging simulation and reduce the computational cost, the initial solution is interpolated from stand-alone sectoral simulations of each component. In terms of approach, the integrated mesh is generated in several steps to solve potential machine dependent memory limitations. It is then observed that the 360 degrees computation converges to an operating point with less than $0.5 \%$ difference in zero-dimensional values compared to the stand-alone simulations yielding an overall performance within $1 \%$ of the designed thermodynamic cycle. With the presented methodology, convergence and azimuthally decorrelated results are achieved for the integrated simulation after only 6 fan revolutions.
\end{abstract}

\section{Introduction}

Industry aims to optimise gas-turbine engines to increase reliability and efficiency, while reducing pollutant and noise emissions to comply with more restrictive regulations. Nowadays, these engines are still designed following individual paths for each component (compressor, combustion chamber, turbine and others) by different departments of the same company. Each component is designed and manufactured individually and then assembled together. An important practical problem that could be encountered is that the resulting engine may exhibit overall poorer performance than the one obtained from the individual component optimisations due to integration effects, possibly requiring additional costly processes due to redesign of the latter. In the design process, 
Computational Fluid Dynamics (CFD) has been progressively adopted from two-dimensional simulations of blade profiles to a more accurate three-dimensional representation of a component. Simulations with the Reynolds-Averaged Navier-Stokes (RANS) method have been the industry's primarily choice, especially for the design of individual components since their computational cost is limited and results are acceptable at nominal conditions (Pinto et al., 2017). Today, as a result of the increase and easier accessibility to computing power, higher fidelity methods such as unsteady RANS (URANS) and Large-Eddy Simulations (LES) are gradually being used (Tucker, 2011a,b; Gicquel et al., 2012; Gourdain et al., 2014; Anand et al., 2021). However, their usage is still mainly limited to academic configurations, and when it is done for industrial engines, it is so to compute periodic sectors of individual components. In such cases, boundary conditions are usually defined either by imposing zero-dimensional single values (average quantities), one-dimensional profiles or steady twodimensional contours on the inlet and outlet boundaries. These can be obtained from the performance cycle of the machine or inherited from the time-averaged solution of an adjacent component (e.g. the turbine stage inlet is inherited from the outlet of the combustion chamber). However, simulations of individual components do not share unsteady information such as turbulence intensity and velocity length scales that are approximated if imposed. As a result of these approximations, bidirectional unsteady interactions between components remain unavailable for simulations of single components. Note finally that ideally and for such compressible flows, acoustic treatments or acoustic impedances should also be prescribed at inlet or outlet since these parameters can greatly impact the stability map of a combustion chamber (Poinsot, 2013) for example or any CFD simulation.

In order to overcome some of the simplifications needed to define flow-boundary specifications of individual components, several attempts have been made to couple two components of the engine. In some works, RANS or LES solvers were used for the combustion chamber and URANS solvers for the turbine (Salvadori et al., 2012; Insinna et al., 2014; Jacobi et al., 2017). Nonetheless, these approaches still lead to strong hypotheses on the information provided from one code to the other, implying approximations on the mass-flow rate, total energy and turbulent quantities. Using a single LES solver to solve the full system constitutes a high potential solution to avoid these approximations (Duchaine et al., 2017; Miki et al., 2018; Thomas et al., 2019; Miki et al., 2020). Such multi-component LES simulations for example accurately represent the critical unsteady high temperature spots issued from the combustion chamber that impact on the turbine blades. An integrated simulation of a radial compressor and a combustion chamber (Pérez Arroyo et al., 2020) demonstrated that the pressure fluctuations generated by the interaction of the impeller with the radial diffuser reach the combustion chamber, potentially modifying the shape of the flame which could change the interaction with an eventual turbine stage.

The first attempt to simulate three components at once was performed by the Center for Turbulence Research at Stanford University (Schlüter et al., 2005; Medic et al., 2007a, b). Their strategy was to use an incompressible LES solver for the combustion chamber and a compressible URANS second solver for the compressor and turbine stages. From a scientific point of view it was a remarkable milestone, however, the methods and framework used to couple the codes were complex and as a result, the integrated simulation failed to produce meaningful results to the author's knowledge. Recently, a cost-efficient RANS-based simulation of the compressor, combustion chamber and turbine stage (Romagnosi et al., 2019) was performed using the Nonlinear Harmonic Method (He and Ning, 1998) to characterise unsteady phenomena. In this case, results are compared against a classical mixing plane approach that by nature, spatially averages variables, which accentuates the need for meaningful unsteady methods to transfer the information at the interfaces between components.

In the current work the first reactive LES of an integrated 360 degrees engine with three main components (fan, compressor and combustion chamber) is presented. The engine considered is the DGEN-380 (Price Induction, Inc. and Akira Technologies). The engine is relatively compact but contains many technological features of current turbofan engines (including combustion) and it is currently used as a demonstrator at NASA and ISAE-SUPAERO. These characteristics make it a good candidate to simulate numerically. However, being a rather new demonstrator, related research is scarce. The associated available literature found can be grouped in 4 categories: performance cycle studies using 0D approximations (Pilet et al., 2011; López de Vega et al., 2019), acoustics and liners research (Berton, 2016; Brown and Sutliff, 2018; Nark et al., 2018; Sutliff et al., 2019; Nagai et al., 2019) including combustion noise (Boyle et al., 2018, 2020), experimental and RANS campaigns at wind-milling conditions (Dufour et al., 2015;García Rosa et al., 2015; Dufour and Thollet, 2016) and experimental as well as LES investigations of the flow around the fan and the Outlet-Guide Vanes (OGV) at the nominal operating point (Odier et al., 2017, 2018).

This study is structured as follows. First, the configuration is introduced and the numerical setup is detailed. Secondly, the methodology to carry out the integrated simulation is explained and a special focus is made on mesh generation and High-Performance Computing (HPC). Thirdly, the initialisation and convergence of the 
360 degrees domain is presented. Then, the flow topology of the transonic compressor is introduced. Finally, main conclusions are listed. Results are analysed in detail and compared against stand-alone LES predictions of each component in the companion paper (Pérez Arroyo et al., 2021).

\section{Configuration and numerical setup}

\section{Configuration}

As mentioned above, the configuration numerically studied corresponds to the DGEN-380 demonstrator and includes the full 360 azimuthal degrees of the fan stage, the compressor and the combustion chamber as a first attempt to simulate the full engine. Results are compared against stand-alone simulations of each component that are performed on a CFD-friendly azimuthal sector of 360/14 degrees for the fan and OGVs, 360/11 degrees for the compressor and 360/13 degrees the combustion chamber. This required the modification of the number of OGVs for the fan from 40 to 42 (Odier et al., 2018), and the number of radial and axial diffuser for the compressor from 19 to 22 and 57 to 55, respectively. The modification of the number of diffuser vanes is performed by increasing the height of the channel while keeping constant the total cross-sectional area to keep an equal mass-flow rate. Nevertheless, due to the small reduction of blade count, no modification of the angle of the radial vanes leading-edge is expected. RANS simulations for the real and modified geometry were performed for the compressor to verify that the operating point was not altered by the geometry simplification. The geometry of the 360 degrees simulation has been simplified according to these modifications in order to have a fair comparison with the stand-alone simulations. Likewise, other non-azimuthally periodic characteristics such as supporting struts or an added ignition fuel injector are not considered for the simulations. The fan stage contains a cylindrical inlet, 14 blades, $42 \mathrm{OGV}$ and the bifurcation into the primary and secondary flows. The radial compressor is composed of 11 main blades and 11 splitter blades, as well as a radial and an axial diffusers composed of 22 and 55 vanes, respectively. The annular combustion chamber contains a contouring casing, the flame-tube and a straight outlet. The liners of the flame-tube include effusion-cooling, primary and dilution holes as well as a double contra-rotating swirler for each azimuthal sector.

The domains of the stand-alone simulations are illustrated in Figure 1a-1c and are detailed in the following. The domain for the fan and OGVs (noted as FAN + OGV) starts at the inlet of the engine and ends at the inlet of the impeller of the radial compressor, where the outlet has been axially extended to ease the evacuation of turbulence. For the secondary flow, it reaches the axial position of the exit of the real engine but no exterior domain has been considered. The domain for the compressor (denoted as CoHP) has a short straight inlet that leads to the impeller, followed by the radial and axial diffusers and exits as a straight annular duct of the same height as the one found on the axial diffusers. Last, the combustion chamber domain (hereafter referred as CC),
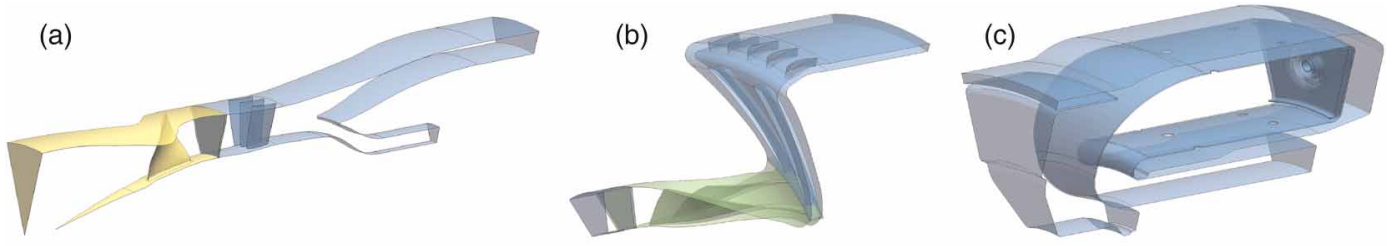

(d)

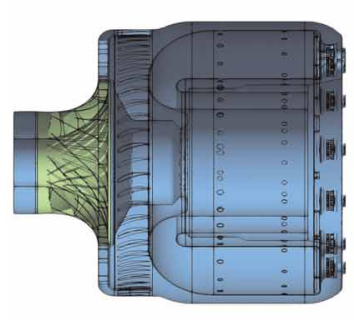

(e)

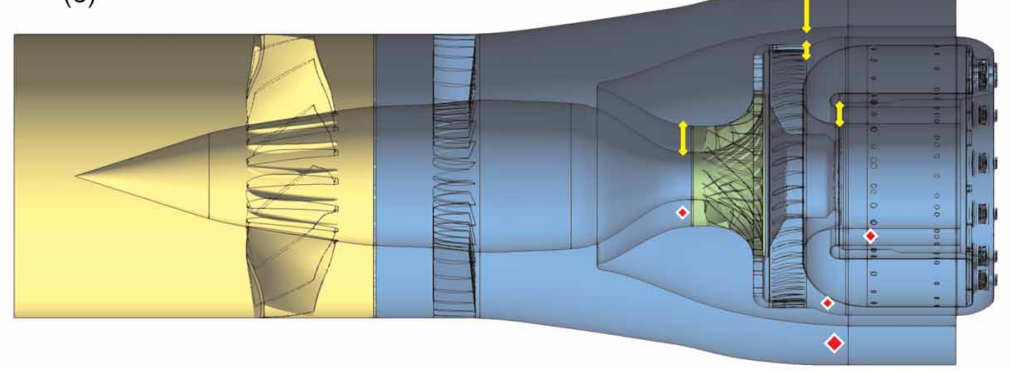

Figure 1. View of the domain for each simulation. Blue depicts the static sub-domains, and green and yellow the rotating sub-domains depending on its rotational speed. Lines and markers in Figure 1e are used as a reference throughout this work. (a) FAN + OGV domain (1 sector). (b) CoHP domain (1 sector). (c) CC domain (1 sector). (d) $\mathrm{COHP}+\mathrm{CC}\left(360^{\circ}\right)$. (e) FULLEST $\left(360^{\circ}\right)$. 
has a straight inlet with no axial diffuser vanes and a straight outlet instead of the turbine stages. The diffuser vanes were not considered for the stand-alone simulation of the chamber because its azimuthal periodicity is different from the one for the chamber. In order to perform the full integrated simulation, first an intermediate 360 degrees computation including the compressor stage and the combustion chamber as depicted in Figure 1d was carried out (noted as CoHP + CC). Finally, the full integrated domain from the fan inlet to the combustion chamber outlet is shown in Figure 1e and related results will be referred to as FULLEST (First fUlL engine computation with Large Eddy SimulaTion).

In this work, the operating point of study corresponds to take-off with opposite rotational speeds of 13,053 and 51,930 rpm for the fan and radial compressor, respectively. The total designed mass-flow rate is $13.846 \mathrm{~kg} / \mathrm{s}$ with a by-pass ratio of 6.84 . On the real engine, an effective suction of $1 \%$ of air is present within the compressor stage through a series of different outlets. In the present simulations this suction is mimicked at a position located on the compressor hub between the impeller and the radial diffuser. In order to ease the comparison against the design operating point, only the effective mass-flow rate after suction will therefore be considered (i.e. the mass-flow entering the combustion chamber). Last, the compressor works at a pressure ratio of 4.6 and the combustion chamber reaches temperatures of roughly $2,500 \mathrm{~K}$ and operates with a fuel to air mass-flow ratio of 0.018 .

\section{Numerical setup}

The reactive as well as the non-reactive LES are performed with the code AVBP, the explicit unstructured and massively parallel compressible flow solver developed by CERFACS (Schönfeld and Rudgyard, 1999). All numerical predictions have been carried out using the explicit second-order scheme Lax-Wendroff (Lax and Wendroff, 1964) and the subgrid-scale model relies on the Wall-Adapting Local Eddy (WALE) viscosity model (Nicoud and Ducros, 1999). Note also that to reduce the computational cost of all simulations, a standard log-law is applied on all solid boundaries with slip conditions (Schmitt et al., 2007). This reduces the cost not only because the total number of cells is reduced but also because it increases the cell size at the wall and thus, the minimum time-step computed through a global Courant-Friedrich-Levy number is increased compared to a wallresolved simulation. For combustion, the thickened-flame model (Colin et al., 2000) is used to account for combustion-turbulence interaction along with a reduced chemistry with 6 species and 2 reactions (Franzelli et al., 2010) where a purely gaseous premixed mixture is injected. In addition, the thickened-hole model (Bizzari et al., 2018) is introduced to represent the micro-perforations in the flame-tube. Non-reflective Navier-Stokes characteristic boundary conditions are used at inlet (Poinsot and Lele, 1992; Odier et al., 2019) and outlet (Granet et al., 2010; Koupper et al., 2015) without any kind of synthetic turbulence. This setup was shown to provide the best trade-off between accuracy and computational cost (Gicquel et al., 2012).

The variables specified as input parameters at inlet and outlet boundaries of the stand-alone simulations are the following. For the FAN + OGV, mass-flow rate and static temperature are defined at the inlet and static pressure at the outlets (different for the primary and secondary flows). The same approach is used for the CC domain whereas for the CoHP, total pressure and temperature are set at the inlet and static pressure at the outlet. The integrated simulation uses the same boundaries as the inlet of the FAN + OGV and the outlet of its secondary flow, along with the outlet of the combustion chamber.

When it applies, the transfer of the flow between the static and rotating sub-domains is performed with an overset grid method over a common geometrical zone for the proper exchange of the necessary information (Wang et al., 2014; de Laborderie et al., 2018). AVBP is based on the SPMD paradigm for parallelism (Single Program - Multiple Data). In the case of this simulation separate in-code instances are automatically generated for static and rotating sub-domains. Each instance is coupled internally using the CWIPI library from ONERA (Refloch et al., 2011; Duchaine et al., 2015). Since there are two different rotational speeds, the integrated simulation FULLEST utilises three instances of AVBP to run as illustrated by Figure 2: one for the static sub-domain,

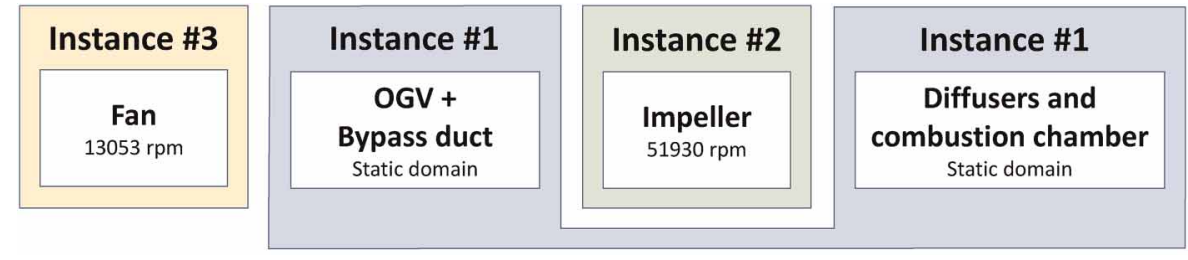

Figure 2. Instance repartition according to the rotational speeds for FULLEST. 
one for the fan sub-domain, and one for the impeller sub-domain. The different instances for the stand-alone simulations are colour-coded according to Figure 1.

Details concerning the mesh used for each simulation are provided in Table 1 along with the wall-clock time per physical millisecond for the given number of cores. All meshes are unstructured and solely made of tetrahedral elements. The FAN + OGV mesh is similar to the "M1" mesh computed by Odier et al. (2017) with $x^{+}=y^{+}=z^{+}$of about 100 for a uniform refinement of $1 \mathrm{~mm}$ and a fan tip-gap discretisation of 17 cells. The CoHP mesh has a uniform mesh refinement of $0.25 \mathrm{~mm}$, a wall refinement of $0.125 \mathrm{~mm}$ and between 7 to 9 cells in the tip-gap of the impeller following the recommendation by Dombard et al. (2018). This leads to average $y^{+}$values of about 150 on the hub and shroud and 75 on the walls of the blades and vanes. The CC mesh has a mesh size of $1 \mathrm{~mm}$ in the contouring casing and the outlet sections far from the walls. The swirler has a refinement of 0.2 to $0.4 \mathrm{~mm}$, with the minimum at the walls and the dilution as well as primary holes are fully refined at $0.2 \mathrm{~mm}$. The walls in the flame-tube are discretised at $0.25 \mathrm{~mm}$ whereas the interior coarsens from 0.4 to $1 \mathrm{~mm}$ as depicted in Figure 3a (Koupper et al., 2018). Overall, $y^{+}$of about 150 are obtained on the external walls, and about 50 on the walls of the flame-tube and swirler. The integrated domain FULLEST keeps the same level of discretisation as the stand-alone simulations at the walls. However the fluid mesh from the impeller to the exit of the combustion chamber has been coarsened by about $5 \%$ in the compressor and the combustion chamber to reduce the total number of cells. As a result, FULLEST which computes the full azimuthal 360 degrees of the machine, uses a mesh that is composed of 2,100 million cells which is over 1 order of magnitude higher than their stand-alone sectoral counterparts. In addition, the smallest cell in the whole domain is found in the tip-gap region of the impeller yielding the most limiting time-step for the entire simulation. Ultimately, the computational cost attains a value of about 300,000 core hours per physical millisecond, i.e. about 350,000 core hours per impeller revolution or about 1.4 million core hours per fan revolution. This integrated simulation has been performed through the access to the supercomputer Joliot-Curie (GENCI/TGCC) on 14,400 Skylake cores over several months consuming 31.6 million hours awarded by PRACE which is in agreement with the estimated cost and mesh size proposed by Anand et al. (2021) (second row in Table 1) for a full engine LES.

\section{Methodology and initialisation}

Regardless of the ability of the codes to perform such extreme simulations, the major difficulty lies in a clever methodology of initialisation to save computational cost complemented by a strategy to yield the best trade-off to solve potential machine dependent memory and HPC limitations (e.g. partitioning). Although menial, these technical and often unavailable details are of paramount importance if one wants to reproduce such simulations. This section presents the methodology used to carry out the integrated simulation FULLEST. In particular, details about the stand-alone simulations are given followed by the approach used to generate the mesh consisting of over 2 billion cells and its associated initial solution, the mesh partitioning procedure, the initialisation and convergence of FULLEST as well as an initial comparison of the operating point between integrated and

Table 1. Details of the simulations.

\begin{tabular}{|c|c|c|c|c|c|c|c|c|c|}
\hline \multirow[b]{3}{*}{ Type of domain } & \multicolumn{5}{|c|}{ Stand-alone simulations } & \multicolumn{4}{|c|}{ Integrated simulations } \\
\hline & \multicolumn{2}{|c|}{$\mathrm{FAN}+\mathrm{OGV}$} & \multicolumn{2}{|l|}{ CoHP } & \multirow{2}{*}{$\begin{array}{l}\text { CC } \\
\text { Static }\end{array}$} & \multicolumn{2}{|c|}{$\mathrm{CoHP}+\mathrm{CC}$} & \multicolumn{2}{|c|}{ FULLEST } \\
\hline & Static & Rotating & Static & Rotating & & Static & Rotating & Static & Rotating \\
\hline Mesh size (in million of cells) & 25 & 27 & 62 & 50 & 62 & 950 & 420 & 1,300 & 800 \\
\hline Periodicity (number of sectors) & \multicolumn{2}{|l|}{14} & \multicolumn{2}{|l|}{11} & 13 & \multicolumn{2}{|l|}{1} & \multicolumn{2}{|l|}{1} \\
\hline Average Time-step (s) & \multicolumn{2}{|c|}{$6.8 e-8$} & \multicolumn{2}{|l|}{$7.9 e-9$} & $1.5 e-8$ & \multicolumn{2}{|c|}{$8.9 e-9$} & \multicolumn{2}{|c|}{$8.9 e-9$} \\
\hline Cost (core hours/ms) & \multicolumn{2}{|l|}{950} & \multicolumn{2}{|l|}{17,000} & 5,000 & \multicolumn{2}{|c|}{180,000} & \multicolumn{2}{|c|}{300,000} \\
\hline Number of cores & \multicolumn{2}{|l|}{540} & \multicolumn{2}{|l|}{4,032} & 2,044 & \multicolumn{2}{|l|}{14,112} & \multicolumn{2}{|c|}{14,400} \\
\hline
\end{tabular}


(a)

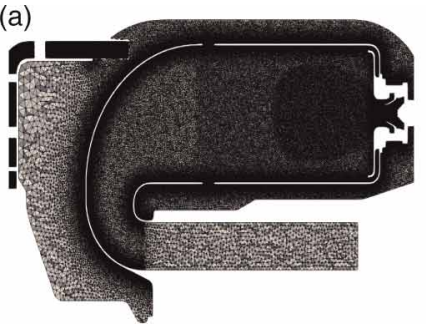

(b)

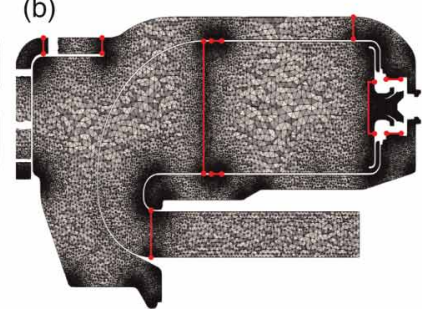

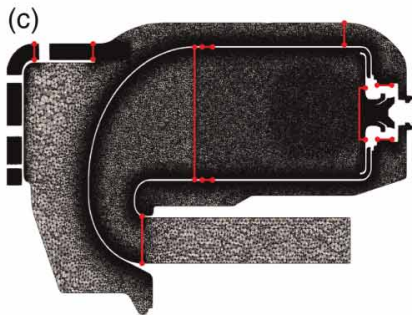

Figure 3. Meridional cut of the mesh for the diffusers and the combustion chamber. (a) Target mesh (1 sector). (b) Coarse mesh $\left(360^{\circ}\right)$. (c) Adapted mesh $\left(360^{\circ}\right)$.

stand-alone simulations. In addition, the flow topology generated by the radial compressor working at transonic conditions is introduced.

\section{Initialisation and convergence of the stand-alone simulations}

Performing the simulations of the stand-alone components has three goals. First, a data-base for each component without any interaction with its surrounding is obtained at a reduced cost. Secondly, such a prediction can then be used as a reference for the integrated simulation. Thirdly, as proposed by Pérez Arroyo et al. (2020), the final (i.e. converged at the correct operating point) instantaneous flow snapshot is used as initial solution of each specific component to launch the integrated simulation. The simulations FAN + OGV were initialised from previous LES solutions provided by Odier et al. (2018), updating the rotational speed of the fan and inlet as well as the outlet boundary conditions. In that case, note that a short trial and error setting period to find a satisfactory static pressure at the outlet boundaries was necessary to ensure the correct bypass ratio. Once the transient finished, data was acquired during 10 fan rotations for flow analysis. Note that as of today, one brute force possibility to initialise compressor simulations is to start with the flow at rest and then increase progressively the rotational speed and outlet pressure as explained by Dombard et al. (2018). Using this approach, convergence would be achieved within 10 revolutions. However in this work, the CoHP simulation was initialised directly from RANS solutions used to verify the geometrical modifications. Using this methodology, convergence was achieved within only 3 impeller revolutions saving up to 140,000 core hours with respect to the initialisation from a flow at rest. This CoHP simulation was then run until convergence and then for 10 rotations for analysis. The CC configuration was initialised from conditions at rest with first a mono-species non-reactive flow to converge the aerodynamics and design point at reduced cost. Once the solution is converged after approximately $20 \mathrm{~ms}$, the gas air (represented by a single species in AVBP) is transformed into a mixture of N2, O2 and the species: $\mathrm{CO}, \mathrm{CO} 2$ and $\mathrm{H} 2 \mathrm{O}$, which are set to zero. Then fuel is injected in a gaseous form inside the vaporiser for about $5 \mathrm{~ms}$ until a recirculation zone of mixed fuel and air is generated in the combustion chamber. The flow is then ignited by adding an energy deposition that mimics a spark. To finish, the simulation is converged after a transient period of about $25 \mathrm{~ms}$ with a flame properly positioned in the flame-tube. Data is then acquired for 50 additional milliseconds for flow analysis which corresponds to about 5 convective flow-through times which is enough to converge root-mean-square (RMS) values.

\section{Generation of the integrated domain and associated mesh}

The static sub-domain for FULLEST is composed of the OGVs, the bypass duct, the radial and axial diffusers as well as the combustion chamber as illustrated in Figure 1e. Furthermore, it is geometrically divided in aft and forward disconnected regions by the impeller sub-domain. The mesh and initial solution of the fan sub-domain, the forward region of the static sub-domain (from fan outlet to compressor inlet) and the impeller sub-domain can be easily constructed by azimuthal repetition of sectoral meshes using the in-house package for manipulating unstructured computational grids HIP (Müller, 1999). The tool HIP is able to merge all replicated surfaces creating a single mesh and associated solution file for all $360^{\circ}$ sub-domains. In fact, only the mesh for the fan subdomain from FAN $+\mathrm{OGV}$ is conserved intact. The sectoral meshes for the OGVs and bypass duct regions are first regenerated with the same refinement parameters as FAN + OGV, taking into account the right geometry connecting to the impeller. For the impeller sub-domain, a new sectoral mesh is created with new refinement parameters. Then, the mesh for the fan sub-domain and the one regenerated for the OGVs and bypass duct region can be repeated 13 times and rotated while the impeller can be duplicated 10 times. 
A particular challenge arises for the aft region of the static sub-domain, i.e. the diffusers and the combustion chamber because they differ in their azimuthal periodicities. For this specific static component junction, if the sectoral meshes were to be repeated azimuthally, a non-conformal interface (not supported by AVBP) would appear between the axial diffuser and the combustion chamber regions. Several solutions were considered to overcome this problem. The generation of a fully 360 degrees refined mesh including the diffusers and the combustion chamber was discarded due to memory limitations to generate such a heavy mesh on our visualisation machine with 64 GB of RAM. The addition of another AVBP instance for the combustion chamber was also tested on a sectoral configuration but it led to an increase in computational cost of over $20 \%$ due to the additional instance and its new interfaces. Ultimately, the solution retained for this work was to generate a 360 degrees coarse mesh that was then refined following a given metric using the library MMG (Dapogny et al., 2014; Daviller et al., 2017). To refine and adapt the mesh, a metric is constructed using the meshes from the stand-alone sectoral simulations as the target mesh (Figure 3a), and using the 360 degrees coarse mesh as input (Figure 3b). The metric is then applied to the local edge size of the cells and it is computed by dividing the cell-averaged edge size of the coarse mesh by the target edge size of the sectoral simulation at each node of the coarse mesh. The edge size value of the target mesh is interpolated on the coarse mesh in order to be able to perform this operation. The mesh adaptation was performed only on the aft region of the considered sub-domain (static sub-domain of CoHP + CC) and due to other technical limitations (currently, MMG is only capable of handling 32-bit integers limiting the size of the domain it can handle), the sub-domain was further divided in 8 zones as depicted in Figure $3 \mathrm{~b}$ by the red boundaries. Each zone is therefore adapted independently and then merged together with HIP. In order to do so and avoid non-matching interfaces, the boundaries of each zone are generated to the target sizes of the initial coarse mesh and are not modified during the adaptation process. Finally, the full static sub-domain for FULLEST is obtained by adding together both aft and forward regions. A view of the resulting mesh for the combustion chamber is illustrated in Figure 3c. Although cumbersome, this procedure was the only way to generate this extreme mesh.

\section{Setup of the initial solution for the integrated domain}

As mentioned above, the initial solution file for the forward region of the engine (including the impeller) was generated by an azimuthal duplication of the last instantaneous converged results from the corresponding stand-alone simulations. Prior to this duplication, the number of species is again transformed following the same procedure as the one used in the stand-alone CC, i.e. change from the mono-species air to the mixture of species used to model combustion and then interpolated in the intermediate sectoral meshes mentioned above for the fan, OGVs and impeller. This is also performed in the axial and radial diffusers. The solution for the aft region (diffusers and combustion chamber) is then obtained in a similar manner as Pérez Arroyo et al. (2020) by performing two partial piecewise linear gradient-based interpolations. First, the CC solution is azimuthally repeated and partially interpolated into the 360 degrees refined $\mathrm{CoHP}+\mathrm{CC}$ mesh. Then, in the second step, the azimuthally repeated solution from the diffusers is partially interpolated onto the CoHP + CC mesh, where the previously interpolated solution is also read and overwritten in the axial diffuser as well as part of the contouring casing.

\section{Efficient mesh partitioning for the integrated domain}

Finally, the mesh and associated solution need to be partitioned in order to launch the simulation in parallel. This was performed for FULLEST utilizing the hierarchical domain decomposition and load balancing tool TREEPART (Mohanamuraly and Staffelbach, 2020). Indeed, FULLEST is out of scope of standard domain decomposition techniques due to the large number of elements and the large number of cores used in the simulations. Traditional domain decomposition libraries such as Parmetis (Karypis and Kumar, 1998) or Pt-Scotch (Chevalier and Pellegrini, 2008), often fail with core counts over 4,000 and with meshes over $700 \mathrm{M}$ elements in the author's experience. This is due to the important memory requirements and global communications used in these libraries. TREEPART was built to account for the local computing machine topology at the hardware level and minimise global communications. In fact it uses one-side MPI 3 communications for all exchanges and only relies on Parmetis for low level graph decompositions. TREEPART can be used at runtime within the code or off-line to generate a parallel mapping file called el2part (each element of the mesh is mapped to a given number of partitions) than can be read by AVBP to perform the simulation reducing initialisation times and ensuring reproducibility. An illustration of the final partitioning is shown in Figure 4 (left). 

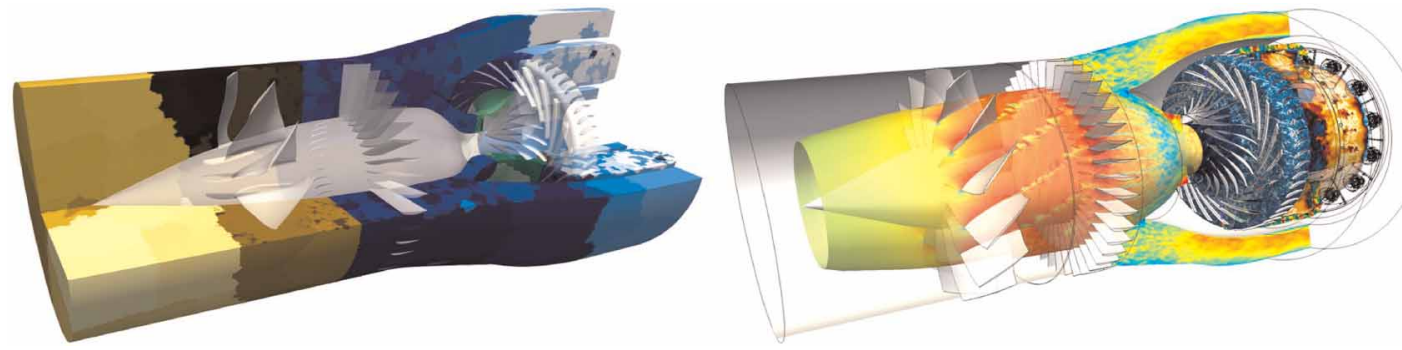

Figure 4. Three-dimensional illustrations of FULLEST. (left) Illustration of the partitioning over 8,820 cores for the static domain (in blue colours), 2,880 cores for the compressor instance (in green colours) and 2,688 cores for the fan instance (in yellow colours). (right) Instantanous contours of FULLEST depicting Mach number in the forward region, density gradients in the compressor, pressure fluctuations in the contouring casing and temperature in the combustion chamber.

\section{From sectoral and stand-alone to 360 degrees and integrated simulations}

The simulation is initialised on the CoHP + CC domain for 6 impeller revolutions in order to ensure that the flow is correctly established between the compressor stage and the combustion chamber at a reduced cost. After this time, the remaining forward section of the engine is added (FULLEST case) and the simulation is run for 26 additional impeller revolutions to eliminate the transient related to the integration from the whole domain and acquire data for analysis. The complexity of this simulation is demonstrated in Figure 4 (right) with an instantaneous snapshot of the entire domain. Figure 5 illustrates the convergence of integral values at 4 axial locations in the domain (see Figure 1e): at the outlet of the secondary flow, at the inlet of the compressor, at the exit of the axial diffuser and at the exit of the combustion chamber. Results are normalised with the zero-dimensional values at those sections. These are averaged quantities in time (steady values) and space (e.g. over an axial plane
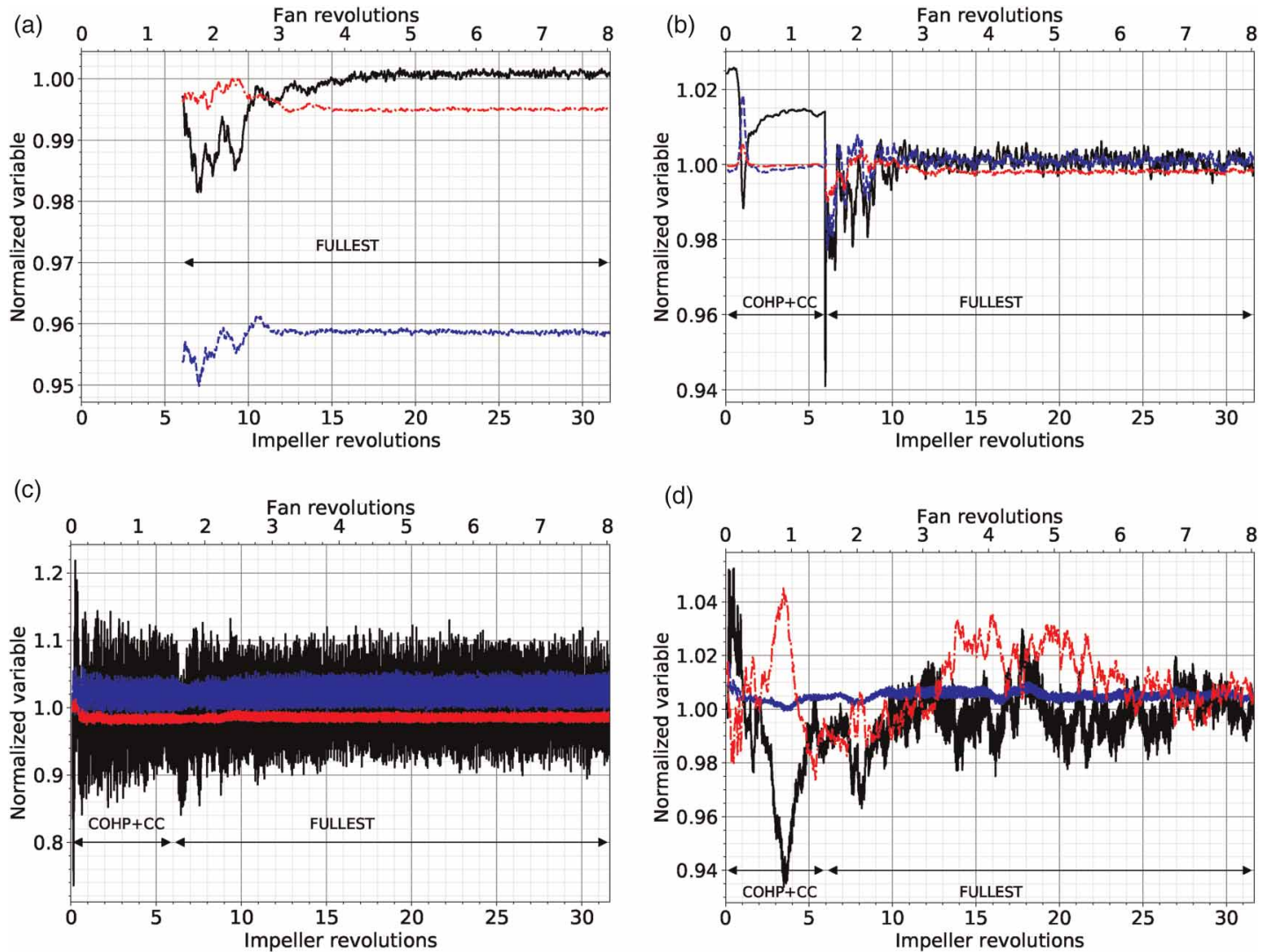

Figure 5. Convergence plots of normalised integral values for (solid black) $\dot{m}$, (dash-dotted red) $T_{t}$ and (dashed blue) $P_{t}$ at four different cross-sectional positions noted in yellow in Figure 1e. Values are normalised by the ones from the thermodynamic cycle. (a) Secondary flow outlet. (b) Impeller inlet. (c) Axial diffuser trailing edge. (d) Combustion chamber exit. 
at the inlet of the machine). These values are used to define the main characteristics of the engine in a design process. The outlet of the secondary flow (Figure 5a) features a transient in mass-flow rate $\dot{m}$ which converges after 2.5 fan revolutions and total pressure $P_{t}$ as well as total temperature $T_{t}$ stabilise after 1.5 fan revolutions. At the impeller inlet (Figure 5b), $\dot{m}$ undergoes a deficit at the end of the first impeller revolution but it stabilises back after 3 revolutions. The apparently temporary loss of mass-flow in the domain is possibly due to a combination of interpolation errors and the adaptation to the new boundary conditions at the inlet of the impeller. When the fan and OGV domains are added, all three variables are suddenly reduced but they stabilise and recover within 6 impeller revolutions. The variance of each variable has been increased with respect to the values at the end of the CoHP + CC simulation which already shows an impact of the unsteadiness introduced by the presence of the Fan and the wakes generated by the OGV. Results after the axial diffuser shown in Figure 5c barely change. Only a minor variation is observed which lasts about 1 impeller revolution after each integration. At the exit of the combustion chamber (Figure 5d), due to its large characteristic time, it is not possible to confirm an effect of the integration on the integral values.

Table 2 shows the comparison against the design operating point for both stand-alone and integrated simulations computed over the last 10 impeller revolutions at different positions of the engine for $\dot{m}$, total temperature $T_{t}$ and total pressure $P_{t}$ deviations expressed in percentage. The subtraction between given values provides a first approximation of how much the simulation can be impacted by the integration. The mass-flow rate is correctly recovered with differences of less than $1 \%$ between the simulations and the operating point and between the stand-alone and the integrated simulations at all locations listed in Table 2. Deviations above $| \pm 1 \%|$ (highlighted in bold) found for $T_{t}$ and $P_{t}$ at some positions are discussed in the following. At the fan inlet, a relative error of $-1.42 \%$ and $-0.74 \%$ are reached for $P_{t}$. This difference, although not substantial could be linked to the fact that the inlet is modelled with a straight duct instead of considering the full nacelle. As previously explained, the static pressure was modified for the secondary flow outlet to obtain the right bypass ratio. In addition, as before, the geometry outside the nacelle is not taken into account in the simulation. As a consequence, a relative error greater than $4 \%$ for $P_{t}$ is achieved for all computations. At the inlet of the combustion chamber, values differ depending on the simulation. For the CoHP case, $T_{t}$ presents a difference of $-2.02 \%$ whereas a discrepancy of $1.85 \%$ is found for $P_{t}$ in the CC case. Differently, as static temperature (CC) and static pressure (CoHP) are set at the inlet and outlet boundary conditions, respectively, these values are closer to the operating point. Similarly, because the FULLEST case does not have any boundary condition at the inlet of the combustion chamber, both variables slightly differ from the thermodynamic cycle. Despite the disparity in $P_{t}$, when this

Table 2. Relative errors of zero-dimensional values for mass-flow, total temperature and pressure between the simulations and the designed operating conditions.

\begin{tabular}{|c|c|c|c|c|c|c|c|}
\hline & & \multicolumn{3}{|c|}{$\begin{array}{l}\text { Stand-alone Vs Operating } \\
\text { Point }\end{array}$} & \multicolumn{3}{|c|}{ FULLEST Vs Operating Point } \\
\hline & & $\dot{m}$ & $T_{t}$ & $P_{t}$ & $\dot{m}$ & $T_{t}$ & $P_{t}$ \\
\hline \multicolumn{2}{|l|}{ Fan inlet } & $-0.04 \%$ & $0.13 \%$ & $-1.42 \%$ & $0.62 \%$ & $0.13 \%$ & $-0.74 \%$ \\
\hline \multicolumn{2}{|l|}{ Secondary flow outlet } & $-0.05 \%$ & $-0.41 \%$ & $-4.76 \%$ & $0.07 \%$ & $-0.45 \%$ & $-4.13 \%$ \\
\hline \multirow[t]{2}{*}{ Impeller inlet } & FAN + OGV & $0.00 \%$ & $-0.13 \%$ & $0.17 \%$ & \multirow[t]{4}{*}{$0.29 \%$} & \multirow[t]{2}{*}{$-0.20 \%$} & \multirow[t]{2}{*}{$0.10 \%$} \\
\hline & $\mathrm{CoHP}$ & $0.74 \%$ & $-0.03 \%$ & $-0.13 \%$ & & & \\
\hline \multirow[t]{2}{*}{ Combustion chamber inlet } & & & $-2.02 \%$ & $-0.02 \%$ & & \multirow[t]{2}{*}{$-1.51 \%$} & \multirow[t]{2}{*}{$2.25 \%$} \\
\hline & $\mathrm{CC}$ & $-0.06 \%$ & $0.10 \%$ & $1.85 \%$ & & & \\
\hline \multicolumn{2}{|l|}{ Exterior primary hole } & - & - & $-0.09 \%$ & - & - & $-0.16 \%$ \\
\hline \multicolumn{2}{|l|}{ Combustion chamber outlet } & $0.11 \%$ & $0.36 \%$ & $0.46 \%$ & $-0.11 \%$ & $0.44 \%$ & $0.54 \%$ \\
\hline
\end{tabular}

FULLEST values averaged over the last 10 impeller revolutions. Reference total temperature used at the combustion chamber outlet is computed from chemical equilibrium with the same chemistry used in AVBP. Values above $1 \%$ are highlighted in bold. 
one is measured on the primary and dilution holes (only values at the exterior primary hole are shown in Table 2 for simplicity) and compared against the designed operating $P_{t}$ at the inlet of the combustion chamber, a similar $P_{t}$ is obtained for both simulations. This suggests that even though $P_{t}$ differs from the operating point at the inlet of the combustion chamber, the values seen by the flame-tube should be in agreement with the operating point. Last, values at the outlet of the combustion chamber show similar $T_{t}$ for both simulations.

During the initialisation, the flow does not only experience the transient developed from adding other components but also an azimuthal decorrelation. This occurs because the initial solution has been azimuthally repeated from the sectoral simulations. This decorrelation is illustrated in Figure 6 using temporal signals extracted from nodes at similar axial locations as the ones used for Figure 5. The decorrelation is calculated by computing the evolution of the Pearson correlation coefficient,

$$
\rho_{X, Y}(n)=\frac{n \sum_{n}^{i=1} x_{i} y_{i}-\sum_{n}^{i=1} x_{i} \sum_{n}^{i=1} y_{i}}{\sqrt{\left[n \sum_{n}^{i=1} x_{i}^{2}-\left(\sum_{n}^{i=1} x_{i}\right)^{2}\right]\left[n \sum_{n}^{i=1} y_{i}^{2}-\left(\sum_{n}^{i=1} y_{i}\right)^{2}\right]}}, \quad n=1, \ldots, N
$$

where $n$ goes from 1 to the total number of iterations $N$ computed in the simulation. The signal $X\left\{x_{1}, \ldots, x_{n}\right\}$ is fixed and used as reference whereas signal $Y\left\{y_{1}, \ldots, y_{n}\right\}$ is extracted from the adjacent azimuthal sector or the opposite azimuthal sector with respect to the position of signal $X$. The evolution of the correlation coefficient is shown for the axial velocity $\left(u_{x}\right), P$ and $T$ at a position close to the outlet of the secondary flow in Figure 6a. All variables remain unaffected for the first fan rotation and then start to drop at different rates. Temperature correlations from both axial positions in the machine drop at the same rate whereas different behaviours are obtained for $u_{x}$ and $P$. Correlations of $u_{x}$ are higher on the closest signal as it would be expected whereas this occurs for the farthest signal for the pressure correlations. Nonetheless, this could be explained by the presence of azimuthal
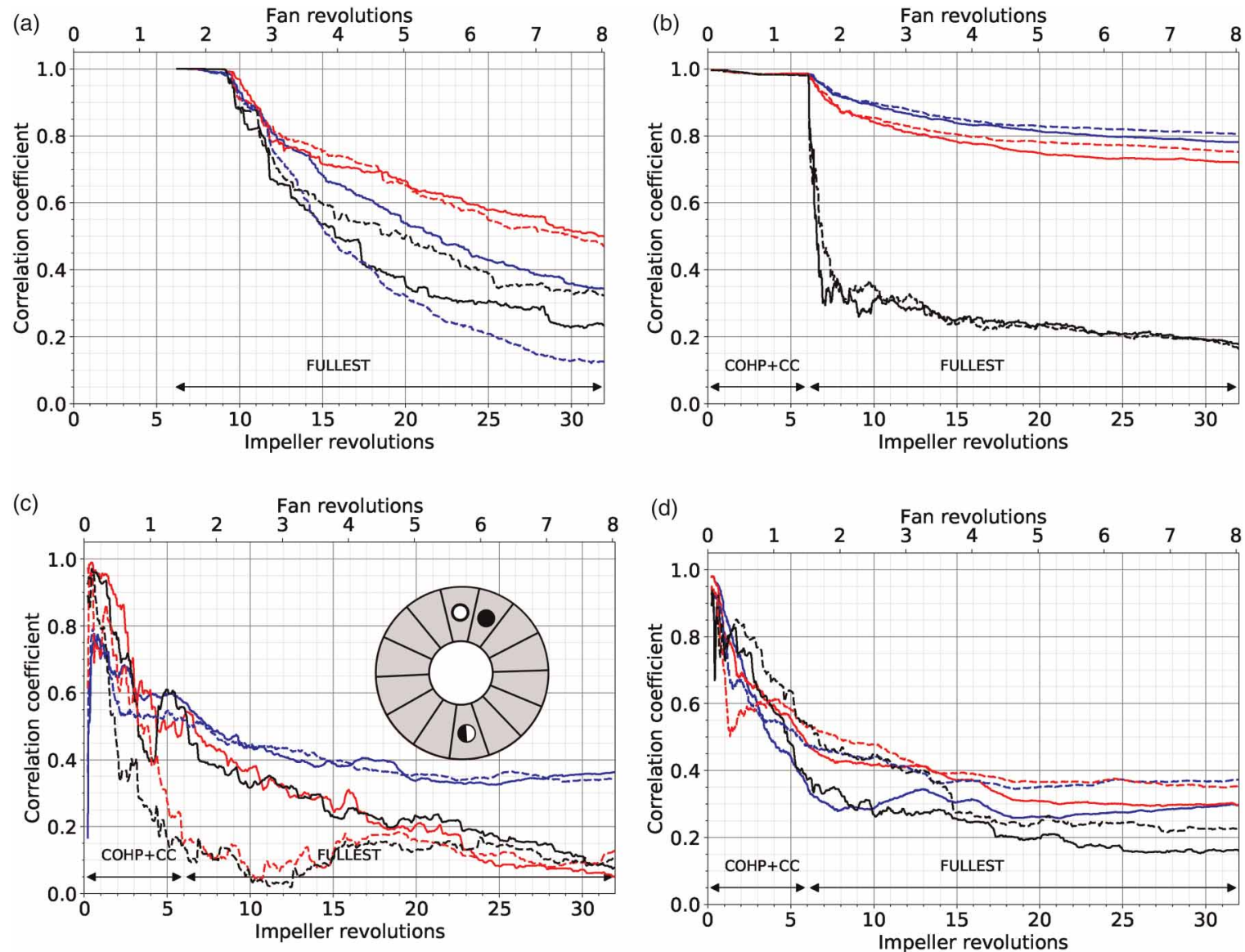

Figure 6. Azimuthal decorrelation plots of local signals for (black) $u_{x}$, (red) $T$ and (blue) $P$ at different positions noted in red in Figure 1e. Solid lines represent the decorrelation with the adjacent azimuthal sector whereas dashed lines illustrate the decorrelation with the opposite azimuthal sector. (a) Secondary flow outlet. (b) Impeller inlet. (c) Exit of the axial diffuser. (d) Combustion chamber exit. 
modes synchronised at these locations. At the inlet of the impeller (Figure 6b), the solution remains azimuthally periodic until the forward section of the static domain is added (case FULLEST). Then, as the periodicity of this section differs from the one of the compressor and receives the wakes from the fan and OGVs, the correlation coefficient suddenly drops for $u_{x}$ and stabilises about 2 fan revolutions later. Pressure and temperature on the other hand decay at a slower rate and to higher values than $u_{x}$. A different behaviour is found after the axial diffusers and at the exit of the combustion chamber as depicted in Figure $6 \mathrm{c}$ and $6 \mathrm{~d}$. As a result of higher turbulence levels coming from each component, the flow decorrelates much faster at these positions than the previous ones. This occurs from the start of the first integration $(\mathrm{CoHP}+\mathrm{CC})$. The second integration (case FULLEST), has no visible impact on the correlation coefficient and they stabilise after about 15 impeller revolutions for the three variables. Results for FULLEST are thus considered azimuthally decorrelated and will not have any history effect coming from the stand-alone simulations.

\section{Upstream propagating shock-wave from the compressor}

The flow topology generated at the inlet of the impeller is presented since it has an impact on the flow around the fan and OGVs. At take-off conditions, the compressor operates in transonic conditions in the rotating frame of reference of the impeller and a shock-wave is formed at the leading edge of the impeller which propagates upstream towards the fan. The shock is generated due to the high impeller rotational speed needed to attain the designed pressure ratio at take-off (Ferri, 1964). The flow field is therefore dominated by a strong shock as depicted in Figure 7 using an instantaneous field at 70\% of the normalised hub-to-shroud distance (denoted hereafter $h / H$ ). Although the Mach number remains below 0.8, the relative Mach number (i.e. the Mach number in the rotating frame of reference) attains values of up to 1.4. This translates in a pressure jump of about $30 \mathrm{kPa}$ across the shock.

Since the shock is anchored at the leading edge of the impeller, it rotates with it. This discontinuity is seen as a propagation in the absolute frame. Disturbances that propagate at subsonic conditions are known to decay exponentially with distance, however, because shock wave evolution is principally an inviscid phenomenon as demonstrated by Prasad (2003), it decays as the inverse of the axial distance from the leading edge (Morfey and Fisher, 1970; Hawkings, 1971). Indeed, far from the rotor and for high pressure jump ratios noted $\Pi$, the shock wave can be expressed for two-dimensional flows as,

$$
\Pi=\frac{2 \gamma}{\gamma+1} \frac{\tau F}{x}, \quad F=M_{\mathrm{rel}}^{-4} \sqrt{\left(M_{\mathrm{rel}}^{2}-1\right)}\left[M_{x} \sqrt{\left(M_{\mathrm{rel}}^{2}-1\right)}-\sqrt{\left(M_{\mathrm{rel}}^{2}-M_{x}^{2}\right)}\right]
$$

where $\gamma$ is the specific heat ratio, $M_{x}$ and $M_{\text {rel }}$ are the axial and relative Mach number, respectively, $\tau$ is the distance between blades and $\Pi$ is the ratio between the pressure difference and the mean pressure across the shock. The pressure jump $\Pi$ is approximated here by the ratio between twice the root-mean-square and the average static pressure averaged azimuthally so that it can be compared against the FAN + OGV case. The shock decay is illustrated in Figure 8 for several $h / H$ ratios from the impeller to the OGVs through the $h / H$ iso-lines depicted in Figure 8. Since this shock is mainly generated on the upper half of the blade span, i.e. above $50 \% \mathrm{~h} / \mathrm{H}$, the increase in $\Pi$ with $h / H$ dominates this upper section as shown in Figure 8. Despite all the approximations, the analytical expression (Equation 2) applied using values at $90 \% \mathrm{~h} / \mathrm{H}$, correctly captures the decay of the shock and shows its ability to propagate upstream through the machine. As expected, FAN + OGV results do not show the high pressure jump of the shock since there is no impeller in the simulation. Further details about this first direct effect of the integration of the fan and OGVs with the compressor is elucidated in the companion paper (Pérez Arroyo et al., 2021).
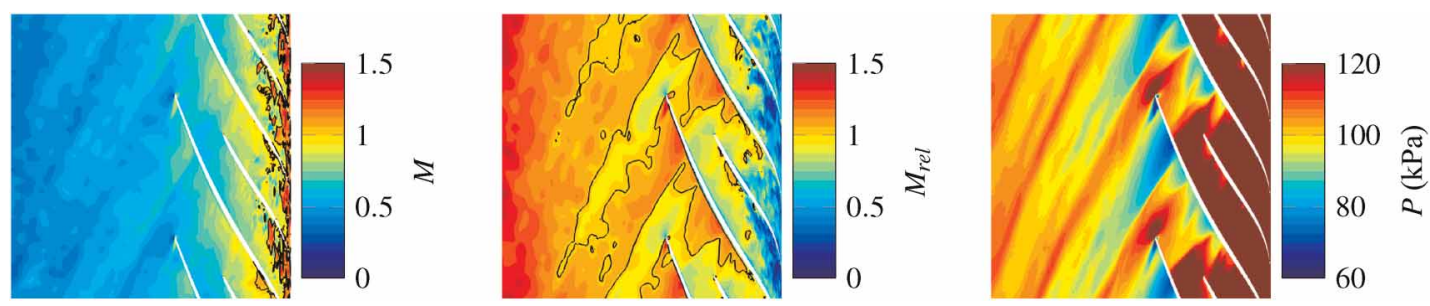

Figure 7. Illustration of the upstream propagating shock at $70 \% \mathrm{~h} / \mathrm{H}$ generated at the leading-edge of the impeller. Black iso-line refers to the sonic line in the relative frame of reference. 

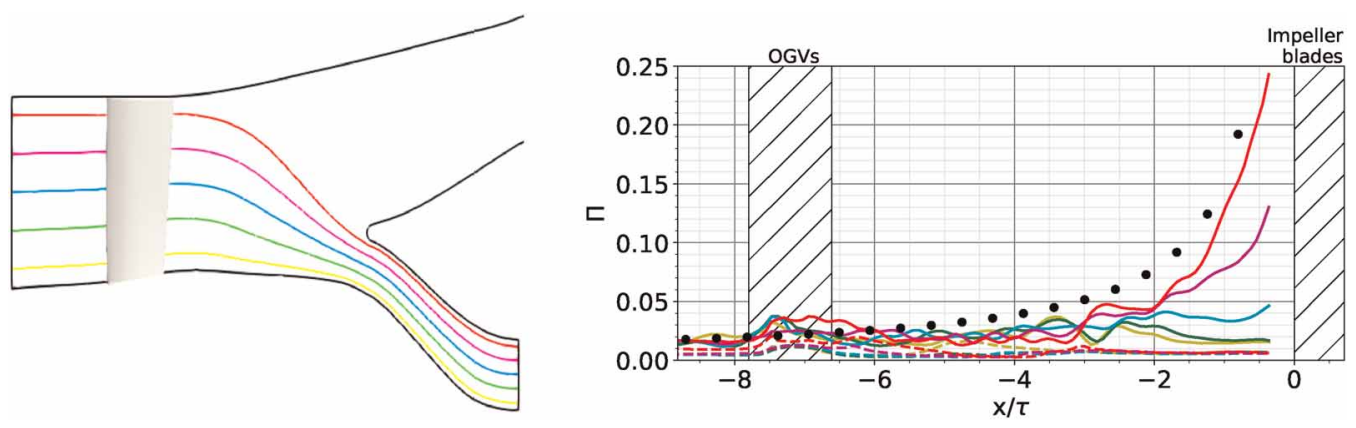

Figure 8 . Normalised pressure jump $\Pi$ at different values of $h / H$ : (yellow) $10 \%$, (green) $30 \%$, (cyan) $50 \%$, (violet) $70 \%$, (red) $90 \%$. (solid) FULLEST, (dashed) FAN + OGV. (•) analytical expression (Equation 2).

\section{Conclusions}

The integrated reactive large-eddy simulation with over 2,100 million cells of a 360 azimuthal degrees gas-turbine including the fan, radial compressor and annular chamber is presented as a means to investigate three main topics: first, the feasibility in terms of cost and methodology of such massive simulations; second, generate a three-dimensional data-base composed of the stand-alone components and the integrated simulation; and third, analyse the effects of the integration of several components thanks to one single simulation.

The configuration of study DGEN-380 is not CFD-friendly in terms of periodicity between components, i.e. the greatest common divisor between blades, vanes and the sectors of the combustion chamber is 1 . Indeed, industrial turbomachinery uses coprime integers for the blade numbers to avoid resonance phenomena and to control the acoustic modes propagated in ducts (Tyler and Sofrin, 1962). In order to reduce the complexity of the problem, the engine has been split in three components: fan and OGVs; centrifugal compressor, including radial and axial diffusers; and combustion chamber. These components have been adapted to a CFD-friendly geometry independently resulting in three different periodicities (1 per component). The methodology introduced by Pérez Arroyo et al. (2020) is then extended to a 360 degrees domain and multiple components of the engine. The CFD-friendly stand-alone components are simulated independently and converged at a relative low cost on periodic domains and then interpolated onto the mesh of the 360 degrees integrated domain which conserves the azimuthal periodicity of each component. Without the prior adaptation of each component to CFD-friendly domains, this methodology could not be applied and the integrated simulation would be initialised from scratch since the solution for each component would not be available. Besides, it enables a fair investigation of the impact of such an integration since they now have the same periodicity for each component. In this work, this procedure saves about 8 million core hours with respect to an initialisation from scratch and in addition generates a data-base of stand-alone component predictions.

Without considering the optimisations for parallel computing and the ability of the code to perform such simulations, the main challenge to overcome has been the generation of the 2,100 million cells mesh for FULLEST. This mesh has been generated in several steps to surpass present memory and software limitations encountered in our work. The generation of the mesh for some of the sub-domains such as the fan, the OGVs and the impeller takes advantage of the initial periodic mesh which is simply repeated azimuthally using the in-house package for manipulating unstructured computational grids HIP (Müller, 1999). This fast mesh generation process is not possible for the forward region of the domain since the diffusers and the combustion chamber do not share the azimuthal periodicity. Instead, the mesh is generated through a complex method of adaptation of a 360 degrees coarse mesh into a refined mesh using the MMG library. Additional tools or extended capabilities in existing mesh generators should continue to be developed to simplify this process since this kind of complex simulations (with different periodicities and components) will be performed regularly in the near future.

The 360 degrees simulation is initialised from the (interpolated) azimuthally repeated sectoral instantaneous solutions of each component and thus at the start, it is identical for each azimuthal sector. This has been analysed by computing the evolution of the correlation between temporal signals at different azimuthal positions. It can be concluded that the flow decorrelates at different rates depending of the location of study. Where the perturbations are smaller like the outlet of the secondary flow, the decorrelation has not yet converged but it is achieved within several impeller revolutions at locations downstream of the compressor. This needs to be considered for example if acoustic measurements are performed and the plane at the exit of the secondary flow is used 
as source to propagate to the far-field or when azimuthal modes are investigated throughout the machine. In addition, the interpolation performed on some sub-domains generates a transient of mass-flow but it is recovered within several fan revolutions, which is faster than the time the flow needs to decorrelate. Both stand-alone and integrated simulations are able to predict physical results and they correctly achieve the expected thermodynamic cycle of the engine with an overall error below 1\%. The impact of the integration on the zero-dimensional values is minimal and only of relevance at the exit of the compressor and inlet of the combustion chamber due to the different boundary conditions. Nonetheless, the integrated simulation FULLEST recovers values of total pressure and temperature in agreement with the exit of CoHP and the inlet of CC, respectively.

Finally, it is concluded that the integration of several components of an engine with LES is challenging but yet feasible. The authors acknowledge that the cost for such 360 degrees LES is still high and possibly limited to big corporations or would require special access to supercomputing resources. This work is a first step towards the LES of a full digital twin of the engine where the turbine stages and the exhaust jet are also considered.

\section{Nomenclature}

\section{Symbols}

$\gamma \quad$ Specific heat ratio $(-)$

$h / H$ Normalised hub-to-shroud distance (-)

$\dot{m} \quad$ Mass-flow $(\mathrm{kg} / \mathrm{s})$

$M \quad$ Mach number (-)

$M_{x} \quad$ Axial Mach number (-)

$M_{\text {rel }}$ Relative Mach number (-)

$P \quad$ Static pressure $(\mathrm{Pa})$

$P_{t} \quad$ Total pressure $(\mathrm{Pa})$

$\Pi \quad$ Normalised pressure jump across the shock (-)

$\tau \quad$ Pitch between blades (m)

$T \quad$ Static temperature $(\mathrm{T})$

$T_{t} \quad$ Total temperature $[\mathrm{K}]$

$u_{x} \quad$ Axial velocity $(\mathrm{m} / \mathrm{s})$

$y^{+} \quad$ Dimensionless wall-coordinate $(-)$

\section{Acronyms}

CFD Computational Fluid Dynamics

CWIPI Coupling With Interpolation Parallel Interface

FULLEST First fUlL engine computation with Large Eddy SimulaTion

LES Large-Eddy Simulation

OGV Outlet-guide vane

PSD Power Spectral Density

RANS Reynolds-Averaged Navier-Stokes

RMS Root-mean-square

SPMD Single Program - Multiple Data

URANS Unsteady-RANS

\section{Acknowledgments}

The authors would like to warmly thank T. Quirante and N. Vieira-Nobre from Akira Technologies for providing the geometry and operating conditions, and N. Buffaz and A. Paillassa from Safran Helicopter Engines for their technical support on the generation of the reduced-count geometry of the compressor and for performing its respective RANS simulations. The authors also gratefully thank G. Exilard and S. Richard from Safran Helicopter Engines for his help during the setup of the micro-perforations in the combustion chamber. 


\section{Funding sources}

These results benefited from funding or developments from projects ATOM (DGAC/SafranTech No. 2018-39), EXCELLERAT (H2020 No. 823691) and EPEEC (H2020 No. 801051). This work was granted access to the HPC resources of GENCI/TGCC (Joliot-Curie supercomputer) on the PRACE allocation project FULLEST (Project No. RA5191).

\section{Competing interests}

Carlos Pérez Arroyo declares that he has no conflict of interest. Jérôme Dombard declares that he has no conflict of interest. Florent Duchaine declares that he has no conflict of interest. Laurent Gicquel declares that he has no conflict of interest. Benjamin Martin declares that he has no conflict of interest. Nicolas Odier declares that he has no conflict of interest. Gabriel Staffelbach declares that he has no conflict of interest.

\section{References}

Anand M., Medic G., Paliath U., Suder K. L., Malik M. R., and Laskowski G. M. (2021). Vision 2030 aircraft propulsion grand challenge problem: Full-engine cfd simulations with high geometric fidelity and physics accuracy, in 'AIAA Scitech 2021 Forum', p. 0956.

Berton J. J. (2016). System noise prediction of the DGEN 380 turbofan engine. Journal of Aircraft. 53 (6): 1779-1786.

Bizzari R., Lahbib D., Dauptain A., Duchaine F., Gicquel L., and Nicoud F. (2018). A thickened-hole model for large eddy simulations over multiperforated liners. Flow, Turbulence and Combustion. 101 (3): 705-717. https://doi.org/10.1007/s10494-018-9909-3

Boyle D. K., Henderson B. S., and Hultgren L. S. (2018). Core/combustor-noise baseline measurements for the DGEN aeropropulsion research turbofan. In: 2018 AIAA/CEAS Aeroacoustics Conference, p. 3281.

Boyle D. K., Henderson B. S., and Hultgren L. S. (2020). DGEN aeropropulsion research turbofan core/combustor-noise measurements: Experiment and modal structure at core-nozzle exit. In: Turbomachinery Technical Conference and Exposition. American Society of Mechanical Engineers.

Brown C. A. and Sutliff D. L. (2018). DGEN aeropropulsion research turbofan (DART): Lossless projection of measured engine noise spectra to a 1-foot-radius arc. In: 2018 AIAA/CEAS Aeroacoustics Conference, p. 3280.

Chevalier C. and Pellegrini F. (2008). Pt-scotch: A tool for efficient parallel graph ordering. Parallel computing. 34 (6-8): 318-331. https://doi.org/10.1016/j.parco.2007.12.001

Colin O., Ducros F., Veynante D., and Poinsot T. (2000). A thickened flame model for large eddy simulations of turbulent premixed combustion. Physics of Fluids. 12 (7): 1843-1863. https://doi.org/10.1063/1.870436

Dapogny C., Dobrzynski C., and Frey P. (2014). Three-dimensional adaptive domain remeshing, implicit domain meshing, and applications to free and moving boundary problems. Journal of Computational Physics. 262: 358-378. https://doi.org/10.1016/j.jcp.2014.01. 005

Daviller G., Brebion M., Xavier P., Staffelbach G., Müller J.-D., and Poinsot T. (2017). A mesh adaptation strategy to predict pressure losses in les of swirled flows. Flow, Turbulence and Combustion. 99 (1): 93-118. https://doi.org/10.1007/s10494-017-9808-z

de Laborderie J., Duchaine F., Gicquel L., Vermorel O., Wang G., and Moreau S. (2018). Numerical analysis of a high-order unstructured overset grid method for compressible LES of turbomachinery. Journal of Computational Physics. 363: 371-398. https://doi.org/10. 1016/j.jcp.2018.02.045

Dombard J., Duchaine F., Gicquel L., Staffelbach G., Buffaz N., and Trébinjac I. (2018). Large eddy simulations in a transonic centrifugal compressor. In: ASME Turbo Expo 2018: Turbomachinery Technical Conference and Exposition. American Society of Mechanical Engineers Digital Collection.

Duchaine F., Jauré S., Poitou D., Quémerais E., Staffelbach G., et al. (2015). Analysis of high performance conjugate heat transfer with the openpalm coupler. Computational Science \& Discovery. 8 (1): 015003. https://doi.org/10.1088/1749-4699/8/1/015003

Duchaine F., Dombard J., Gicquel L., and Koupper C. (2017). On the importance of inlet boundary conditions for aerothermal predictions of turbine stages with large eddy simulation. Computers \& Fluids. 154: 60-73. https://doi.org/10.1016/j.compfluid.2017.05.024

Dufour G., García Rosa N., and Duplaa S. (2015). Validation and flow structure analysis in a turbofan stage at windmill. Proceedings of the Institution of Mechanical Engineers, Part A: Journal of Power and Energy. 229 (6): 571-583. https://doi.org/10.1177/ 0957650915587144

Dufour G. and Thollet W. (2016). Body force modeling of the aerodynamics of the fan of a turbofan at windmill. In: Turbo Expo: Power for Land, Sea, and Air, Vol. 2C, American Society of Mechanical Engineers.

Ferri A. (1964.) Aerodynamic Properties of Supersonic Compressors, Vol. 10. Princeton, NJ: Princeton University Press.

Franzelli B., Riber E., Sanjosé M., and Poinsot T. (2010). A two-step chemical scheme for kerosene-air premixed flames. Combustion and Flame. 157 (7): 1364-1373. https://doi.org/10.1016/j.combustflame.2010.03.014

García Rosa N., Dufour G., Barènes R., and Lavergne G. (2015). Experimental analysis of the global performance and the flow through a high-bypass turbofan in windmilling conditions. Journal of Turbomachinery. 137 (5): 051001. https://doi.org/10.1115/1.4028647

Gicquel L. Y., Staffelbach G., and Poinsot T. (2012). Large eddy simulations of gaseous flames in gas turbine combustion chambers. Progress in Energy and Combustion Science. 38 (6): 782-817. https://doi.org/10.1016/j.pecs.2012.04.004

Gourdain N., Sicot F., Duchaine F., and Gicquel L. (2014). Large eddy simulation of flows in industrial compressors: A path from 2015 to 2035. Philosophical Transactions of the Royal society A: Mathematical, Physical and Engineering Sciences. 372 (2022): 20130323. https://doi.org/10.1098/rsta.2013.0323

Granet V., Vermorel O., Léonard T., Gicquel L., and Poinsot T. (2010). Comparison of nonreflecting outlet boundary conditions for compressible solvers on unstructured grids. AIAA Journal. 48 (10): 2348-2364. https://doi.org/10.2514/1.J050391 
Hawkings D. (1971). Multiple tone generation by transonic compressors. Journal of Sound and Vibration. 17 (2): 241-250. https://doi. org/10.1016/0022-460X(71)90458-5

He L. and Ning W. (1998). Efficient approach for analysis of unsteady viscous flows in turbomachines. AIAA Journal. 36 (11): 2005-2012. https://doi.org/10.2514/2.328

Insinna M., Salvadori S., and Martelli F. (2014). Simulation of combustor/NGV interaction using coupled RANS solvers: Validation and application to a realistic test case. In: ASME Turbo Expo 2014: Turbine Technical Conference and Exposition, American Society of Mechanical Engineers Digital Collection.

Jacobi S., Mazzoni C., Rosic B., and Chana K. (2017). Investigation of unsteady flow phenomena in first vane caused by combustor flow with swirl. Journal of Turbomachinery. 139 (4): 041006. https://doi.org/10.1115/1.4035073

Karypis G. and Kumar V. (1998). Multilevelk-way partitioning scheme for irregular graphs. Journal of Parallel and Distributed computing. 48 (1): 96-129. https://doi.org/10.1006/jpdc.1997.1404

Koupper C., Gicquel L., Duchaine F., and Bonneau G. (2015). Advanced combustor exit plane temperature diagnostics based on large eddy simulations. Flow, Turbulence and Combustion. 95 (1): 79-96. https://doi.org/10.1007/s10494-015-9607-3

Koupper C., Lamouroux J., Richard S., and Staffelbach G. (2018). High resolution large eddy simulations to evaluate turbulence properties within a real helicopter engine combustor. In: Turbo Expo: Power for Land, Sea, and Air, Vol. 4A: Combustion, Fuels, and Emissions, American Society of Mechanical Engineers, p. V04AT04A006.

Lax P. D. and Wendroff B. (1964). Difference schemes for hyperbolic equations with high order of accuracy. Communications on Pure and Applied Mathematics. 17 (3): 381-398. https://doi.org/10.1002/cpa.3160170311

López de Vega L., Dufour G., and García Rosa N. (2019). A fully coupled body force-engine performance methodology for boundary layer ingestion. In: AIAA Propulsion and Energy 2019 Forum, p. 3828.

Medic G., You D., and Kalitzin G. (2007a). On coupling of RANS and LES for integrated computations of jet engines. In: ASME Turbo Expo 2007: Power for Land, Sea, and Air, American Society of Mechanical Engineers Digital Collection, pp. 1181-1187.

Medic G., You D., Kalitzin G., Herrmann M., Ham F., et al. (2007b). Integrated computations of an entire jet engine. In: ASME Turbo Expo 2007: Power for Land, Sea, and Air, American Society of Mechanical Engineers Digital Collection, pp. 1841-1847.

Miki K., Moder J., and Liou M.-S. (2018). Computational study of combustor-turbine interactions. Journal of Propulsion and Power. 34 (6): 1529-1541. https://doi.org/10.2514/1.B36909

Miki K., Wey C. T., and Moder J. (2020). Computational study of modeling fully-coupled combustor-turbine interactions by the open national combustion code (openncc). In: AIAA Propulsion and Energy 2020 Forum, p. 3689.

Mohanamuraly P. and Staffelbach G. (2020). Hardware locality-aware partitioning and dynamic load-balancing of unstructured meshes for large-scale scientific applications. In: Proceedings of the Platform for Advanced Scientific Computing Conference, pp. 1-10.

Morfey C. and Fisher M. (1970). Shock-wave radiation from a supersonic ducted rotor. The Aeronautical Journal. 74 (715): 579-585. https://doi.org/10.1017/S0001924000049095

Müller J.-D. (1999). Coarsening 3-D hybrid meshes for multigrid methods. In: 9th Copper Mountain Multigrid Conference, Citeseer.

Nagai K., Oinuma H., and Ishii T. (2019). Acoustic liner test of DGEN 380 turbofan engine. In: INTER-NOISE and NOISE-CON Congress and Conference Proceedings, Vol. 259, Institute of Noise Control Engineering, pp. 6078-6088.

Nark D. M., Jones M. G., and Sutliff D. L. (2018). Broadband inlet liner design for the DGEN aero-propulsion research turbofan. In: 2018 AIAA/CEAS Aeroacoustics Conference, p. 3608.

Nicoud F. and Ducros F. (1999). Subgrid-scale stress modelling based on the square of the velocity gradient tensor. Flow, Turbulence and Combustion. 62 (3): 183-200. https://doi.org/10.1023/A:1009995426001

Odier N., Duchaine F., Gicquel L. Y., Dufour G., and Garcia Rosa N. (2017). Comparison of LES and RANS predictions with experimental results of the fan of a turbofan. In: Proceedings of 12th European Conference on Turbomachinery Fluid dynamics \& Thermodynamics.

Odier N., Duchaine F., Gicquel L., Staffelbach G., Thacker A., et al. (2018). Evaluation of integral turbulence scale through the fan stage of a turbofan using hot wire anemometry and large eddy simulation. In: Turbo Expo: Power for Land, Sea, and Air, Vol. 2C: Turbomachinery, American Society of Mechanical Engineers, p. V02CT42A021.

Odier N., Sanjosé M., Gicquel L., Poinsot T., Moreau S., and Duchaine F. (2019). A characteristic inlet boundary condition for compressible, turbulent, multispecies turbomachinery flows. Computers \& Fluids. 178: 41-55. https://doi.org/10.1016/j.compfluid.2018. 09.014

Pérez Arroyo C., Dombard J., Duchaine F., Gicquel L., Odier N., et al. (2020). Large-eddy simulation of an integrated high-pressure compressor and combustion chamber of a typical turbine engine architecture. In: Turbomachinery Technical Conference and Exposition, American Society of Mechanical Engineers.

Pérez Arroyo C., Dombard J., Duchaine F., Gicquel L., Martin B., et al. (2021). Towards the large-eddy simulation of a full engine: Integration of a 360 azimuthal degrees fan, compressor and combustion chamber. Part II: Comparison against stand-alone simulations. Global Power and Propulsion Society. 5: 1-16.

Pilet J., Lecordix J.-L. C., Garcia-Rosa N., Barènes R., and Lavergne G. R. (2011). Towards a fully coupled component zooming approach in engine performance simulation. In: Turbo Expo: Power for Land, Sea, and Air, Vol. 1: Aircraft Engine; Ceramics; Coal, Biomass and Alternative Fuels; Wind Turbine Technology, pp. 287-299.

Pinto R. N., Afzal A., D’Souza L. V., Ansari Z., and Samee A. M. (2017). Computational fluid dynamics in turbomachinery: A review of state of the art. Archives of Computational Methods in Engineering. 24 (3): 467-479. https://doi.org/10.1007/s11831-016-9175-2

Poinsot T. (2013). Simulation methodologies and open questions for acoustic combustion instability studies. In: Annual Research Briefs, Center for Turbulence Research, Standford University, Stanford, CA, pp. 179-188.

Poinsot T. J. and Lele S. (1992). Boundary conditions for direct simulations of compressible viscous flows. Journal of Computational Physics. 101 (1): 104-129. https://doi.org/10.1016/0021-9991(92)90046-2

Prasad A. (2003). Evolution of upstream propagating shock waves from a transonic compressor rotor. The Journal of Turbomachinery. 125 (1): 133-140. https://doi.org/10.1115/1.1516813

Refloch A., Courbet B., Murrone A., Villedieu P., Laurent C., et al. (2011). CEDRE software. Aerospace Lab. 1-10. 
Romagnosi L., Li Y., Mezine M., Teixeira M., Vilmin S., et al. (2019). A methodology for steady and unsteady full-engine simulations. In: Turbo Expo: Power for Land, Sea, and Air, Vol. 2C: Turbomachinery, American Society of Mechanical Engineers, p. V02CT41A002.

Salvadori S., Riccio G., Insinna M., and Martelli F. (2012). Analysis of combustor/vane interaction with decoupled and loosely coupled approaches. In: ASME Turbo Expo 2012: Turbine Technical Conference and Exposition, American Society of Mechanical Engineers Digital Collection, pp. 2641-2652.

Schlüter J., Apte S., Kalitzin G., vd Weide E., Alonso J., and Pitsch H. (2005). Large-scale integrated LES-RANS simulations of a gas turbine engine. Annual Research Briefs. 111-120.

Schmitt P., Poinsot T., Schuermans B., and Geigle K. (2007). Large-eddy simulation and experimental study of heat transfer, nitric oxide emissions and combustion instability in a swirled turbulent high-pressure burner. Journal of Fluid Mechanics. 570: 17-46. https://doi. org/10.1017/S0022112006003156

Schönfeld T. and Rudgyard M. (1999). Steady and unsteady flow simulations using the hybrid flow solver AVBP. AIAA Journal. 37 (11): 1378-1385. https://doi.org/10.2514/2.636

Sutliff D. L., Jones M. G., and Nark D. M. (2019). Acoustic directivity and insertion loss measurements of advanced liners installed the inlet of the DGEN aeropropulsion research turbofan, NASA TM.

Thomas M., Dombard J., Duchaine F., Gicquel L., and Koupper C. (2019). Large eddy simulation of combustor and complete singlestage high-pressure turbine of the FACTOR test rig. In: ASME Turbo Expo 2019: Turbomachinery Technical Conference and Exposition, American Society of Mechanical Engineers Digital Collection.

Tucker P. (2011a). Computation of unsteady turbomachinery flows: Part 1-Progress and challenges. Progress in Aerospace Sciences. 47 (7): 522-545. https://doi.org/10.1016/j.paerosci.2011.06.004

Tucker P. (2011b). Computation of unsteady turbomachinery flows: Part 2-LES and hybrids. Progress in Aerospace Sciences. 47 (7): 546-569. https://doi.org/10.1016/j.paerosci.2011.07.002

Tyler J. M. and Sofrin T. G. (1962). Axial flow compressor noise studies, Technical report, Society of Automotive Engineers Transactions Technical Paper.

Wang G., Duchaine F., Papadogiannis D., Duran I., Moreau S., and Gicquel L. Y. (2014). An overset grid method for large eddy simulation of turbomachinery stages. Journal of Computational Physics. 274: 333-355. https://doi.org/10.1016/j.jcp.2014.06.006 